\title{
A Structural Equation Model of Elderly Health Care in the Surveyed Households in Kumbakonam Town, Tamil Nadu, India
}

\author{
Mrs. G. Renugadevi* and Dr. S. Vadivel** \\ *Assistant Professor, Department of Geography, Govt. College for Women (Autonomous), \\ Kumbakonam-612 001, \\ **Assistant Professor, Post Graduate and Research Department of Geography, Government Arts College \\ (Autonomous), Kumbakonam-612 002,
}

\begin{abstract}
Introduction: Aged persons are having health problems like hearing and vision decline, muscle strength diminishes, less flexibility of skin and blood vessels, and an overall decline of physique. Their body's organ performs insufficiently with advancing age. Intelligence were also diminishes with age. The social isolation that often exists among older people can dramatically influence mental attitudes and behaviour. The Indian aged population is currently the second largest in the world. The absolute number of the over 60 population in India will increase from 76 million in 2001 to 137 million by 2021. The functional ability of elderly people is crucial to how well they cope with activities of daily living, which in turn affects their quality of life. Therefore, the purpose of this study to examine the causal relationships among factors determining elderly health.

Objectives: 1) to study the socio-economic profile of the aged people, 2) to identify the health status of elderly person, 3) to examine the causal relationships among factors determining elderly health, and 4) to evaluate whether all the measures fit the recommended value, indicating a good fit of the structural model for the collected data.

Methodology: A systematic random sample of 900 elderly people aged above 58 were interviewed from 45 wards, in each ward 20 persons were selected with health problems. The data on different factors were collected through questionnaire survey using 5 point Likert scale method. The causal relationships were established by structural equation modelling (SEM) method using SPSS and AMOS statistical software.

Conclusion: The SEM fitted to the elderly health care data adequately. The results indicated that, the mental health, caring, family environment, life style, health expenditure had significant effect on physiological status $(\mathrm{p}<0.05)$. These factors had significant relationship on elderly health.
\end{abstract}

Key Words: Structural Equation Model, Healthcare Management, Elderly healthcare

\section{INTRODUCTION}

Aged persons are having health problems like hearing and vision decline, muscular strength diminishes less flexibility of skin and blood vessels, and an overall decline of physique. The organ performs insufficiently with advancing age. Intelligence were also diminishes with age. The social isolation that often exists among older people can dramatically influence mental attitudes and behaviour. The Indian aged population is currently the second largest in the world. The absolute number of the aged over 60 year's population in India will increase from 76 million in 2001 to 137 million by 2021 . The functional ability of elderly people is crucial to how well they cope with activities of daily living, which in turn affects their quality of life.

Structural Equation Modelling (SEM) is a multivariate technique, which estimates a series of interrelated dependence relationships simultaneously. The term Structural Equation Modelling conveys that the causal processes under study are represented by a series of structural (i.e. regression) equations, and that these can be modelled pictorially to enable a clearer conceptualization of the study. The hypothesized model can be tested statistically in a simultaneous analysis of the entire system of variables to determine the extent to which it is consistent with the data. If the goodness-of-fit is adequate, the model argues for the plausibility of postulated relations among the variables. Therefore, the purpose of this study is to examine the causal relationships among factors determining elderly health. 


\section{REVIEW OF LITERATURE}

Choice of Health care facility is a complex issue. There are several intricate factors, governed by diverse socio-physical determinants. Access to healthcare is the capacity to pay, clinic operation times, feeling you have the right, ability or interest to access services (Bernard et al,, 2004), to the physical setting of healthcare service sites (Tanser, 2006). Access to the healthcare has also been defined on basis of the travel time considering the availability of own vehicle and public transportation especially for elderly (Izumiyama et al, 2007). Access to health care in general can be thought of in a number of ways, including based on geographic location, wait-list times, availability of needed information and service quality (Torgerson et al., 2006).

The public service providers are inexpensive but are overburdened (Shiva Kumar et al., 2011) leading to extremities in high waiting time and underutilization due to poor quality. The elderly, sometimes with their limited mobility, becomes fully dependent on companions to take them to the healthcare units. The Socio demographic factors, social group structure, knowledge about disease are significantly related to the individual's medical orientation. Wirick, (1966) argued that individual's resource is the most significant for demand of healthcare. Transportation availability, costs and facility characteristics also interact with distance in affecting people's use of healthcare (Joseph et al, 1984). The disaggregated level analysis of the people's behaviour when they fall sick reveals that in a given period of illness, the patient makes healthcare decision in stages (Christianson J B, 1976).

The majority of elders are outside the social safety net, and they face economic, health, and emotional insecurity and inequity that pose a challenge to an already overburdened societal system (Alam M, 2004). The new millennium has seen a concerted global effort to mainstream aging into the development agenda, and countries have agreed to link questions of aging to frameworks for social and economic development and human rights (United Nations Report, 2002).

Depressive disorders are the leading cause of burden of disease in high-income countries such as the United States (WHO, 2008). Providing appropriate care to the rapidly growing number of older adults in the U.S. with neuropsychiatric conditions represents a major public health challenge (Jeste et al, 1999). This is particularly true for older Latino adults, who are not only the fastest growing sub-population of older American adults (Angel and Whitfield, 2007; U.S. Census Bureau, 2003), but also have significantly higher rates of unipolar depressive disorders compared to non-Hispanic Whites (Aranda, Lee, and Wilson, 2007; Brennan, Vega, Garcia, Abad \& Friedman, 2005; Sorkin, Pham and Ngo-Metzger, 2009).

The research on older people's health has been mostly focused on specific dimension or disease, studied one at a time. Recently, original investigations have made new concepts and perspectives of global health difficulties in the elderly. The first phenotypes of frail adults (Fried et al. 2001) were criticized to be comprised just of physical functioning (Hogan et al. 2003). The following definitions were expanded to include various domains of health, such as such mobility, psychological, cognitive and sensorial problems (e.g. Pel-Little et al. 2009).

While there is controversy concerning what aspects to consider, there is consensus that having health problems is a concept separated from chronic diseases. With this regard, several researches have showed that measures of frailty were associated with mortality independently of illnesses (Puts et al. 2005a, b, c). Salomon et al. (2003) suggested that not selecting medical condition as a domain of multidimensional health was in line with the spirit of the WHO Constitution (1948) and the advancements of the WHO family of classification systems. That is, the diseases are not equated with health status itself, but conceptualized as a possible cause that makes more difficult achieving specific functions or good level of global health (Salomon et al. 2003).

The need to study whether an individual with present multiple problems has been progressively more emphasized (Rockwood et al. 2000, Bortz 2002, Hogan et al. 2003). However, recent research has demonstrated that older people's health cannot be fully described by one global dimension. In fact, such a simple approach misses to describe all the complexity of its multifaceted structure (Brayne et al. 2001, Meinow et al. 2006). In consequence of that, it has become increasingly clear that studying elderly population needs approaches that allow for multiple measures of health to embrace all its complexity (Lafortune 2009, Hallerod 2009). one's state of health is routinely reported to be a major determinant of happiness, particularly in older age groups (Gerstorf et al., 2008), but it is also well established that happy people live longer than unhappy people, even controlling state of health at baseline (Deeg and van Donneveld, 1989; Headey, Hoehne \& Wagner, 2013).

Zhang (2002) used SEM to study the relationships between Quality of Healthy Life (QHL), Quality of Objective Environment (QOE) and Psychological Well-Being (PWB). In Keller, Ware and their fellow researchers' paper (1998), the SEM method was used and a second ordered confirmatory factor analysis model was performed to verify their hypothesis about health status indicators with data from ten countries. 


\section{Objectives}

The objectives of the present study are as follows:

1. To study the socio-economic profile of the aged people,

2. To identify the health status of elderly person,

3. To examine the causal relationships among factors determining elderly health, and

4. To evaluate whether all the measures fit the recommended value, indicating a good fit of the structural model for the collected data.

\section{Data Collection and Sample}

\section{METHODOLOGY}

A systematic random sample of 900 elderly people aged above 58 were interviewed from 45 wards, in each ward 20 persons were selected. The data on different factors were collected through questionnaire survey using 5 point Likert scale method (5 indicating strongly agree and 1 indicating strongly disagree) was used for the present study. The collected information is related to socio-economic, cultural, demographic, psychological characters, health status, health problems and healthcare utilization. However, to find out the physiological status height, weight and body mass index were measured.

\section{DATA ANALYSIS}

The information collected through the questionnaire has been transformed into 74 selected variables and entered into SPSS for the application of statistical technique. These variables are assumed to be the vital factor in determining the health status of elderly people. Factor analysis was employed for the present data structure and accordingly 22 out of 74 variables were extracted. Further, with the help of Analysis of Moment Structure (AMOS) software package, Structural Equation Modelling (SEM) was used for data analysis to find out the measures fit of recommended value, indicating a good fit of the structural model for the collected data.

\section{Socio-Economic Backgrounds of Elderly}

\section{FINDINGS AND DISCUSSION}

Of the 900 elderly people 50 per cent male and 50 per cent female, 60.4 per cent are aged 58 to 68 years, 27.0 per cent are aged 69 to 78 years, 12.1 per cent are 79 to 89 years and remaining 0.5 per cent are aged up to the 103 years. The elderly unmarried are (2.0\%), married (73.2\%), widow (18.0\%), widower $(6.6 \%)$ and divorced $(0.2 \%) .82 .4$ per cent of the respondent's income were Rs. $<100,000,14.2$ per cent were 100,001 to $200,000,2.6$ per cent were 200,001 to 300,000 and 0.8 per cent were $>300,001$. Their previous occupations have been as house wife/own work (35.4\%), agriculture (1.4\%), agricultural labour (1.0\%), labour (41.3\%), private job $(6.9 \%)$, government job $(8.3 \%)$ and business $(5.6 \%)$.

At present, the elderly economically depend on their daughter $(6.4 \%)$, son $(49.0 \%)$, husband/wife $(17.2 \%)$, pension $(8.8 \%)$, business $(9.6 \%)$, aged pension $(8.7 \%)$ and granddaughter $(0.3 \%) .89 .9$ per cent are Hindus, 6.0 per cent are Muslims and 4.1 per cent are Christians. They belong to backward (63.6\%), most backward $(29.1 \%)$, scheduled caste $(4.8 \%)$, scheduled tribe $(0.4 \%)$ and other $(2.1 \%)$ communities. Their educational status was elementary $(46.2 \%)$, middle school $(21.8 \%)$, high school (16.7\%), higher secondary/diploma (2.6\%), bachelor degree $(1.1 \%)$, master degree $(0.6 \%)$ and illiterate $(11.1 \%)$. 72.6 per cent and 27.1 per cent of the aged people were have been living in own house and rented house respectively. Their house are thatched roof with mud walls $(4.8 \%)$, thatched roof with red bricks $(10.1 \%)$, tiled house with mud wall $(3.4 \%)$, tiled house with red bricks $(46.3 \%)$, thokuppu house $(2.9 \%)$, single storey buildings $(30.3 \%)$ multi storeys buildings $(1.8 \%)$ and temple $(0.3 \%)$.

Table-1: Rotated component matrix ${ }^{\mathrm{a}}$

\begin{tabular}{|c|c|c|c|c|c|c|c|}
\hline \multirow{2}{*}{$\begin{array}{l}\text { Variable } \\
\text { Number }\end{array}$} & \multirow[t]{2}{*}{ Name of the Variable } & \multicolumn{6}{|c|}{ Component } \\
\hline & & 1 & 2 & 3 & 4 & 5 & 6 \\
\hline Py 3 & $\begin{array}{l}\text { Feeling no one having } \\
\text { affection }\end{array}$ & 0.849 & & & & & \\
\hline Py 2 & $\begin{array}{l}\text { Feeling no one respect by } \\
\text { ageing }\end{array}$ & 0.794 & & & & & \\
\hline Py 6 & $\begin{array}{l}\text { Hesitate to disclose health } \\
\text { problems }\end{array}$ & 0.777 & & & & & \\
\hline Py 5 & $\begin{array}{l}\text { Problem for accompanying to } \\
\text { hospital }\end{array}$ & 0.749 & & & & & \\
\hline Py 10 & Feels family burden & 0.629 & & & & & \\
\hline Py 9 & Reasons for not caring & 0.525 & & & & & \\
\hline $\mathrm{Ph} 23$ & Can you do your work by & & 0.876 & & & & \\
\hline
\end{tabular}


A Structural Equation Model of Elderly Health Care in the Surveyed Households in Kumbakonam ..

\begin{tabular}{|c|c|c|c|c|c|c|}
\hline & yourself? & & & & & \\
\hline $\mathrm{Ph} 22$ & $\begin{array}{l}\text { Can you walk without other } \\
\text { helps }\end{array}$ & 0.855 & & & & \\
\hline $\mathrm{Ph} 25$ & $\begin{array}{l}\text { Can you do morning work by } \\
\text { yourself }\end{array}$ & 0.824 & & & & \\
\hline $\mathrm{Ph} 11$ & $\begin{array}{l}\text { Working without any physical } \\
\text { strain }\end{array}$ & 0.433 & & & & \\
\hline $\mathrm{Ph} 10$ & Who care about your health? & & 0.712 & & & \\
\hline Se 7 & Family Income From & & 0.708 & & & \\
\hline Py 12 & $\begin{array}{l}\text { Feels happy playing } \\
\text { grandson/daughter }\end{array}$ & & 0.617 & & & \\
\hline Se16 & Number of Son & & -0.615 & & & \\
\hline $\mathrm{Pb} 12$ & Habits of consuming Alcohol & & & 0.911 & & \\
\hline $\mathrm{Pb} 16$ & Smoking behaviour & & & 0.903 & & \\
\hline $\mathrm{Fb} 11$ & $\begin{array}{l}\text { Eating together with family } \\
\text { members }\end{array}$ & & & & 0.670 & \\
\hline $\mathrm{Ph} 26$ & Walking practise & & & & 0.666 & \\
\hline $\mathrm{Ph} 4$ & Present Health Conditions & & & & 0.562 & \\
\hline $\mathrm{Ph} 14$ & Health expenditure (Monthly) & & & & & 0.673 \\
\hline $\mathrm{Ph} 12$ & Physical problems/Diseases & & & & & 0.666 \\
\hline $\mathrm{Ph} 1$ & Weight & & & & & 0.495 \\
\hline
\end{tabular}

Extraction method: Principal component analysis.

Rotation method: Varimax with Kaiser Normalizations

a. Rotation converged in 4 iterations.

\section{Exploratory Factor Analysis}

Factor analysis is used to discover a smaller number of factors underlying larger number of observed variables. The application of factor analysis for the present study is very useful in separating the major dimensions of elderly health conditions. Six dimensions were extracted and contributing a total variance of 56.167 per cent. An Eigen value of 1.0 is taken as a cut-off point to determine the number of dimensions to be extracted. Correlation matrix revealed the presence of many coefficients of 0.4 and above. The Kaiser-MeyerOklin (KMO) measure of sampling adequacy value (MSA) is 0.755 , exceeding the recommended value of 0.6 and the Barlett's Test of Sphericity reached statistical significance $(\mathrm{p}<0.001)$, supporting the factorability of the correlation matrix. Principal components analysis revealed the presence of six components with Eigen values exceeding 1.0.

The correlations between the variable and factor values are shown as the rotated factor loadings in the following table-1. For a good factor solution, a particular variable should load high on one factor and low on all other factors in the rotated factor matrix (Ajai and Sanjaya, 2006). As per the table-1, it can be inferred that out of 74 of selected variables, 22 items are having more than 0.50 factor loadings. These 22 items were taken for further analysis with six components.

\section{Model fit assessment: Structural equation modelling (SEM):}

Structural equation modelling was used to analyze the suitability of the model based upon the selected variables. As recommended by Anderson and Gerbing (1988), measurement model to test the reliability and validity of the survey instrument was analyzed first, and by using AMOS version 20 the structural model was analyzed. The structural equation model (SEM) is the most useful when assessing the causal relationship between variables as well as verifying the compatibility of the model used (Peter, 2011).

Structural equation modelling evaluates whether the data fit a theoretical model. In order to evaluate the model, emphasis was given to Chi-square/degrees of freedom (x2/df), CFI, GFI, AGFI, TLI, IFI, RMSEA and PGFI (Table-2). As per the result, Chi square statistics with $P=0.328$ which is greater than 0.05 , Therefore, it shows a good fit of the model. Consequently, this model is considered for further interpretation in the goodness of fit measures. Common model-fit measures like chi-square/degree of freedom (x2/df), the comparative fit index (CFI), root mean square error of approximation (RMSEA), the normated fit index (NFI), incremental fit index (IFI), and the Tucker Lewis index (TLI) were used to estimate the measurement model fit. Table-2 shows the estimates of the model fit indices from AMOS structural modelling. 
Table-2: Fit statistics of the Measurement model

\begin{tabular}{|l|l|l|c|}
\hline & Fit statistic & Recommended & Obtained \\
\hline 1 & Chi Square & - & 3.442 \\
\hline 2 & df & $p=>0.05$ & 3 \\
\hline 3 & Chi Square significance & $\leq 5.0$ ( Hair et al., 1998) & 0.328 \\
\hline 4 & Chi Square/df & 0.90 ( Hair et al. 2006) & 1.147 \\
\hline 5 & Goodness of Fit Index (GFI) & 0.90 (Daire et al., 2008) & 0.999 \\
\hline 6 & Adjusted Goodness of Fit Index (AGFI) & $\geq 0.90$ (Hu and Bentler, 1999) & 0.990 \\
\hline 7 & Normated Fit Index (NFI) & 0.90 Hu and Bentler, 1999 & 0.980 \\
\hline 8 & Relative Fit Index (RFI) & $0.90($ Hu and Bentler, 1999) & 1.000 \\
\hline 9 & Comparative Fit index (CFI) & $\geq 0.90$ ( Hair et al., 1998) & 0.997 \\
\hline 10 & Tucker Lewis Index (TLI) & $<0.05$ (Hair et al., 2006) & 0.013 \\
\hline 11 & $\begin{array}{l}\text { Root mean square error of approximation } \\
\text { (RMSEA) }\end{array}$ & $<0.02$ (Hu and Bentler, 1990) & 0.032 \\
\hline 12 & Root Mean Square Residual (RMR) & Within 0.05(Mulaik et al., 1989) & 0.107 \\
\hline 13 & Parsimony goodness-of-fit index (PGFI) & & \\
\hline
\end{tabular}

\section{AMOS-Output: Compiled by Author}

According to Gerbing and Anderson (1992), the criteria for an acceptable model are as follows: RMSEA of 0.08 or lower; CFI of 0.90 or higher; and NFI of 0.90 or higher. The fit between the data and the proposed measurement model can be tested with a chi-square goodness-to-fit (GFI) test where the probability is greater than or equal to 0.9 indicates a good fit (Hu and Bentler, 1999). The GFI of this study was 0.999 more than the recommended value of 0.90 the other measures fitted satisfactorily; AGFI=0.990, CFI=1.000, TLI=0.997, IFI=1.000, NFI=0.997 with $\mathrm{x} 2 / \mathrm{df}<3$ at 1.47 and RMSEA=0.013 (Bagozzi and Yi, 1988) and $\mathrm{RMR}=0.032$ indicate a good absolute fit of the model. Goodness of fit indices support the model fit and these emphasized indices indicate the acceptability of this structural model. For the purpose of testing the model fit null hypothesis and alternative hypothesis are framed.

\section{Hypothesis}

Null hypothesis $\left(\boldsymbol{H}_{\boldsymbol{0}}\right)$ : The hypothesized model has a good fit.

Alternate hypothesis $\left(\boldsymbol{H}_{1}\right)$ : The hypothesized model does not have a good fit.

According to the Table-2, it clearly shows that values of all the items are above the suggested value of 0.5 (Hair et al., 2006). According to Bollen (1989a), the higher the probability associated with Chi-square, the closer the fit between the hypothesized model and the perfect fit. The test of our null hypothesis $\mathrm{H}_{0}$, is a sixfactor structure as shown in Figure-1and 2, give up a chi-square value of 3.442 with 3 degrees of freedom and the calculated $\quad \mathrm{P}$ value is 0.328 which is greater than 0.05 which indicates perfectly fit. It is suggesting that the fit of the data to the hypothesized model is entirely adequate. As per the result, Chi square statistics with $\mathrm{P}=$ 0.328 shows a good fit of the model. However, this model is considered for further interpretation in the goodness of fit measures.

According to Barbara (2009), both the sensitivity of the Likelihood ratio test to sample size and its basis on the chi-square distribution, which assume that the population (that is, $\mathrm{H}_{0}$ is correct), have led to problems of fit are now widely known. According to Joreskog and Sorbom (1993), chi-square statistic equals (N-1) $\mathrm{F}_{\min }$, (sample size-1, multiplied by the minimum fit function) this value tends to be substantial when the model does not hold and when sample size is large. Barbara (2009) stated that, researchers have addressed the chi-square limitations by developing goodness-of-fit indices that take a more practical approach to the evaluation process. Hair et al. (1998) suggested the value for the fit statistic minimum discrepancy/degrees of freedom (CMIN/DF), otherwise chi-square/ degrees of freedom as $\leq 5.0$. As per the Table-2, the value for the chi-square/degrees of freedom is 1.147 which is less than the accepted cut off value of $\leq 5.0$

Table-3: Regression Weights: (Group number 1 - Default model)

\begin{tabular}{|l|l|l|c|c|c|c|c|}
\hline \multicolumn{2}{|c|}{ Variables } & $\begin{array}{c}\text { Unstandardized } \\
\text { co-efficient }\end{array}$ & S.E. & $\begin{array}{c}\text { Standardized } \\
\text { co-efficient }\end{array}$ & $\begin{array}{c}\text { Critical } \\
\text { Ratio (t) }\end{array}$ & P Value \\
\hline $\begin{array}{l}\text { Physiological } \\
\text { Status }\end{array}$ & $<---$ & Mental Health & .032 & .011 & .074 & 2.946 & $<0.003^{* *}$ \\
\hline $\begin{array}{l}\text { Physiological } \\
\text { Status }\end{array}$ & $<--$ & Caring & .109 & .007 & .383 & 15.360 & $<0.001^{* *}$ \\
\hline $\begin{array}{l}\text { Physiological } \\
\text { Status }\end{array}$ & $<---$ & Life style & .103 & .040 & .069 & 2.561 & $<0.010^{* *}$ \\
\hline
\end{tabular}


A Structural Equation Model of Elderly Health Care in the Surveyed Households in Kumbakonam ..

\begin{tabular}{|l|l|l|c|c|c|c|c|}
\hline $\begin{array}{l}\text { Physiological } \\
\text { Status }\end{array}$ & $<---$ & $\begin{array}{l}\text { Health } \\
\text { Expenditure }\end{array}$ & .028 & .004 & .166 & 6.679 & $<0.001^{* *}$ \\
\hline $\begin{array}{l}\text { Physiological } \\
\text { Status }\end{array}$ & $<---$ & $\begin{array}{l}\text { Family } \\
\text { Environment }\end{array}$ & .197 & .017 & .299 & 11.755 & $<0.001^{* *}$ \\
\hline $\begin{array}{l}\text { Elderly } \\
\text { Health }\end{array}$ & $<---$ & $\begin{array}{l}\text { Physiological } \\
\text { Status }\end{array}$ & .555 & .056 & .527 & 9.924 & $<0.001^{* *}$ \\
\hline $\begin{array}{l}\text { Elderly } \\
\text { Health }\end{array}$ & $<---$ & Life style & .150 & .057 & .095 & 2.627 & $<0.009^{* *}$ \\
\hline
\end{tabular}

Note: $* *$ denotes significant at $1 \%$ level

\section{Significance tests of individual parameters}

The above table- 3 is demonstrating the unstandardized coefficients and associated test statistics. The amount of change in the dependent or mediating variable for each one unit change in the variable predicting it is symbolized by the unstandardized regression coefficient. The Table- 3 shows the unstandardized estimate, its standard error (abbreviated S.E.), and the estimate divided by the standard error (abbreviated C.R. for Critical Ratio is t. value). Under the column $\mathrm{P}$, the probability value associated with the null hypothesis that the test is zero is exhibited.

\section{Level of significance for regression weight}

The coefficient of Mental Health is 0.032 representing the partial effect of Mental Health on elderly Physiological Status, holding the other variables as constant. The estimated positive sign implies that such effect is positive that elderly Physiological Status would increase by 0.032 for every unit increase in Mental Health and this coefficient value is significant at 1 per cent level.

The coefficient of Caring is 0.109 representing the partial effect of Caring on elder's Physiological Status, holding the other variables as constant. The estimated positive sign implies that such effect is positive that elder's Physiological Status would increase by 0.109 for every unit increase in Caring and this coefficient value is significant at 1 per cent level.

The coefficient of Life Style is 0.103 representing the partial effect of Life Style on elder's Physiological Status, holding the other variables as constant. The estimated positive sign implies that such effect is positive that elder's Physiological Status would increase by 0.103 for every unit increase in Life Style and this coefficient value is significant at 1 per cent level.

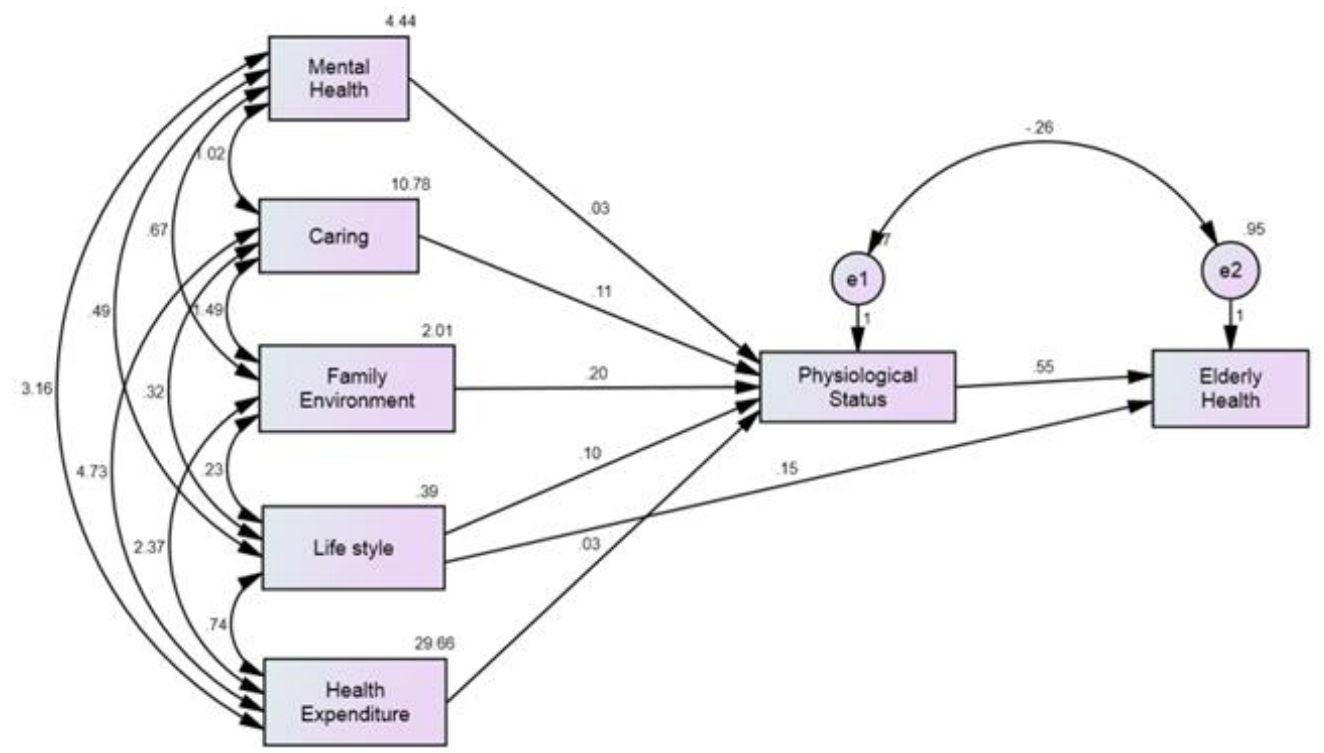

Figure-1: SEM- on Elderly Health: Unstandardized Coefficients

The coefficient of Health Expenditure is 0.028 representing the partial effect of Health Expenditure on elder's Physiological Status, holding the other variables as constant. The estimated positive sign implies that such effect is positive that elder's Physiological Status would increase by 0.028 for every unit increase in Health Expenditure and this coefficient value is significant at 1 per cent level. 


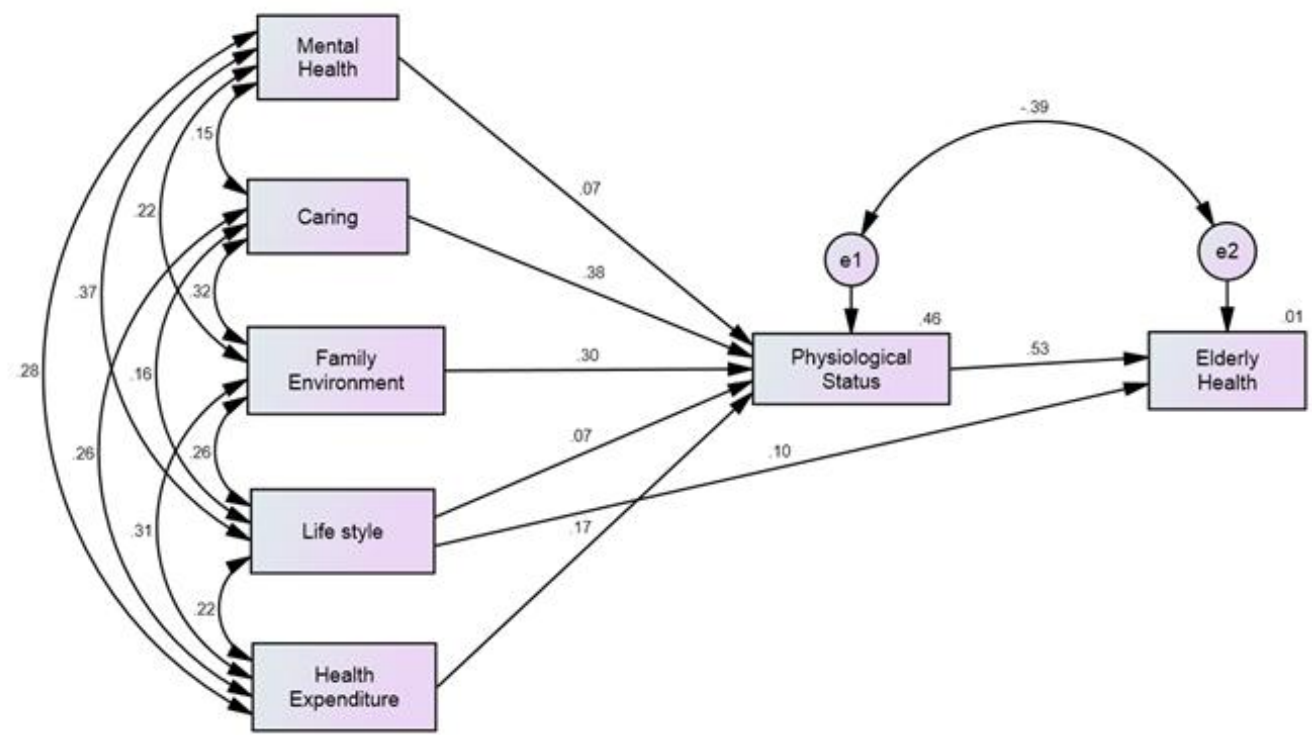

Figure-2: SEM-on Elderly Health: Standardised Coefficients

The coefficient of Family Environment is 0.197 representing the partial effect of Family Environment on elder's Physiological Status, holding the other variables as constant. The estimated positive sign implies that such effect is positive that elder's Physiological Status would increase by 0.197 for every unit increase in Family Environment and this coefficient value is significant at 1 per cent level.

The coefficient of Physiological Status is 0.555 representing the partial effect of Physiological Status on Elderly Health, holding the other variables as constant. The estimated positive sign implies that such effect is positive that the Elderly Health would increase by 0.555 for every unit increase in Physiological Status and this coefficient value is significant at 1 per cent level.

The coefficient of Life Style is 0.150 representing the partial effect of Life Style on Elderly Health, holding the other variables as constant. The estimated positive sign implies that such effect is positive that the Elderly Health would increase by 0.150 for every unit increase in Life Style and this coefficient value is significant at 1 per cent level.

\section{Scalar estimates (group number 1 - default model) \\ Maximum likelihood estimates}

Table-3 is also illustrating the standardized estimates for the fitted model. Relative contributions of each predictor variable to each outcome variable can be evaluated by standardized estimates. Figure 1 and 2 show the Elderly Health Status structural model. Out of 74 variables, 22 variables were taken for confirmatory factor analysis. As per Figure 1 and 2, it is clear that the elderly health status and its determinant variables.

Confirmatory factor analysis is furthermore known as measurement model. The root mean square error of approximation enlightens us how the model would fit the population covariance matrix (Byrne, 1998). According to Kline (2005), CFI, RMSEA can be utilized along with Chi-Square test to calculate the measurement model fit. As an alternative to Chi-square test, goodness-of-fit statistic (GFI) formed by Joreskog and Sorbom, (1993) is able to calculate the proportion of variance (Tabachnick and Fidell, 2007).

Model can be evaluated with the help of Normated fit index by means of comparing the Chi-square value of the model with Chi-square of the null model (Bentler and Bonnet, 1980). CFI is important in all SEM programs because its measure is least affected by sample size (Fan et al., 1999). According to McDonald and Ho (2002), CFI, GFI, and the NFI are the most frequently used fit indices in structural equation modelling.

\section{CONCLUSION}

The aim of this present study is to carry out an experimental analysis of the factors determining the elderly health status. The six factors mental health, caring, family environment, life style, health expenditure and physiological status pertaining to elderly health status model, using a structural equation modelling. This study affirms and develops an instrument of determining factors in the context of elderly health and it examines the relationship among aged people's background. The proposed model is then calibrated using the data collected from aged people in Kumbakonam town of Tamil Nadu. Based on the confirmatory factor analysis, it can be concluded that, the elderly health status scale used in this study adequately fit into the collected data.

As a result, this finding reveals that the hypothesized six-factor model fits the sample data. Based on the feasibility and statistical significance of essential factor estimates; the considerably good fit of the model 
shown in Figure 1 and 2 representing an adequate description of elderly health status structure goodness of fit indices support the model fit and these underline indices indicated the adequacy of this structural model. Absolutely, this study will be useful for the population studies, health science, social science and medical researchers to determine the significance of aged people's health factors.

\section{REFERENCES}

[1]. Ajai GS, Sanjaya GS (2008). Statistical methods for practice and research: A guide to data analysis using SPSS, Response books, New Delhi. p. 143.

[2]. Alam M. (2004) Ageing, old age income security and reforms: An exploration of Indian situation. Econ Polit Wkly 2004; 39: 3731_40.

[3]. Anderson, J. C., and Gerbing, D. W. (1988). Structural equation modelling in practice: A review and recommended two-step approach. Psychological Bulletin, 103, 411-423.

[4]. Angel, J., \& Whitfield, K. (2007). Hispanic Health and Ageing in the Americas. Springer, New York.

[5]. Aranda, M., Lee, P., \& Wilson, S. (2001. Correlates of depression in older Latinos. Home Health Care Services Quarterly, 20(1), 1-20.

[6]. Bagozzi RP, Yi Y (1988). On the evaluation of structural equation models. J. Acad. Mark. Sci. 16(1):7494.

[7]. Barbara MB (2009). Structural Equation Modelling with AMOS. Basic concepts, applications, and programming. 2nd Edn, Routledge, Taylor \& Francis Group, New York. pp. 76-84.

[8]. Bentler PM, Bonnet DC (1980). Significance Tests and Goodness of Fit in the Analysis of Covariance Structures, Psychol. Bull. 88(3):588-606.

[9]. Bernard, D., Quine, S., Kang, M., Alperstein, G., Usherwood, T., Bennett, D., and Booth, M. (2004). "Access to primary health care for Australian adolescents: how congruent are the perspectives of health service providers and young people, and does it matter?",Australian and New Zealand Journal of Public Health 28(5).

[10]. Bollen KA (1989a).Structural equations with latent variables, New York: Wiley.

[11]. Brayne, C., Matthews, F. E., McGee, M. A. and Jagger, C. 2001. Health and ill-health in the older population in England and Wales. Age and Ageing, 30: 53-62.

[12]. Brennan, M., Vega, M., Garcia, I., Abad, A., \& Friedman, M.B. (2005). Meeting the mental health needs of elderly Latinos affected by depression: implications for outreach and service provision. Care Management Journals, 6(2), 98-106.

[13]. Byrne BM (1998). Structural Equation Modelling with LISREL, PRELIS and SIMPLIS: Basic concepts, applications and programming. Mahwah, New Jersey: Lawrence Erlbaum Associates.

[14]. Christianson, J B. (1976). "Evaluating locations for medical care facilities", Land Economics; pp.298313.

[15]. Deeg, D. and van Donneveld (1989) 'Does happiness lengthen life?' In R.Veenhoven ed. How Harmful Is Happiness? Rotterdam, Erasmus University Press, chap. 5. Epidemiology. 51(11): 1179-1188

[16]. Fan X, Thompson B, Wang L (1999). Effects of Sample Size, Estimation Methods, and Model Specification on Structural Equation Modelling Fit Indexes. Struct. Equ. Model. 6(1):56-83.

[17]. Gerbing DW, Anderson JC (1992). Monte Carlo evaluations of goodness of fit indices for structural equation models. Social. Methods Res. 21(2):132-160.

[18]. Gerstorf, D., Ram, N., Roecke, C., Lindenburger, U. and Smith, J. (2008) Decline in life satisfaction in old age: longitudinal evidence for links to distance-to-death, Psychology and Aging, 23, 154-68.

[19]. Hair JF, Anderson RE, Tantham RL (2006). Multivariate Data Analysis.10th edn., Prentice Hall: New Jersey. In: Malek AL- Majali, Nik Kamariah Nik Mat (2011). "Modeling the antecedents of internet banking service adoption (IBSA) in Jordan: A Structural Equation Modeling (SEM) approach”. Journal of Internet Banking and Commerce. 16(1):8-13.

[20]. Hair JF, Anderson RE, Tatham RL, Black WC (1998), Multivariate Data Analysis, Prentice- Hall, Upper Saddle River, New Jersey. In: Marcin Pont and Lisa McQuilken (2002). Testing the Fit of the BANKSERV Model to BANKPERF Data. ANZMAG conference proceedings. 865 .

[21]. Hallerod, B. 2009. Ill, worried or worried sick? Inter-relationships among indicators of wellbeing among old people in Sweden. Ageing and Society, 29: $563-584$.

[22]. Headey, B.W., Hoehne, G. and Wagner G.G. (2013) Does religion make you healthier and longer lived? Evidence for Germany, Social Indicators Research, published online (Dec. 24).

[23]. Hogan, D. B., MacKnight C. and Bergman H. 2003. Models, definitions and criteria of frailty. Aging Clinical and Experimental Research, 15: 3 - 29.

[24]. Hu LT, Bentler PM (1999). Cut off Criteria for Fit Indexes in Covariance Structure Analysis: Conventional Criteria versus New Alternatives, Struct. Equ. Model. 6(1):1-55. 
[25]. Izumiyama, Hiroshi., Ohmori, Nobuaki., \& Harata, Noboru. (2007). "Space-time accessibility measures for evaluating mobility-related social exclusion of the elderly", Proceedings of TRANSED 2007.

[26]. Joreskog K, Sorbom D (1993). LISREL 7: User's Reference Guide. Chicago, IL: Scientific Software International Inc. In: Barbara M Byrne, Structural equation modeling with AMOS, Routledge, Taylor Francis. 2. 76-77

[27]. Joseph \& Philips. (1984). "Accessibility and utilization: Geographical perspectives on Health care delivery", Harper \& Row, New York.

[28]. Keller, S. D., Ware, J. E., Bentler, P. M., Aaronson, N. K., etc (1998). Use of Structural Equation Modeling to Test the Construct Validity of the SF-36 Health Survey in Ten Countries: Results from the IQOLA Project. Journal of Clinical Epidemiology. 51(11): 1179-1188.

[29]. Kline RB (2005). Principle and practice of Structural equation modeling. 2nd Edn. In: Hooper D, Coughlan J,Mullen M R (2008). "Structural Equation Modelling: Guidelines for Determining Model Fit." The Electronic Journal of Business Research Methods. 6 (1): 53 - 60

[30]. Kumar, AK Shiva., Chen, Lincoln C., Choudhury, M., Ganju, S., Mahajan, V., Sinha, A., Sen, A. (2011). "Financing Health care for all: Challenges \& opportunities", The Lancet, vol. 377, issue. 9766, pp.668679.

[31]. Lafortune, L., Beland, F., Bergman, H. and Ankri, J. 2009. Health status transitions in community-living elderly with complex care needs: a latent class approach. BMC Geriatrics, 9: 1 - 14.

[32]. McDonald RP, Ho MHR (2002). Principles and Practice in Reporting Statistical Equation Analyses. Psychol. Methods 7(1):64-82.

[33]. Meinow, B., Parker, M. G., Kareholt, I. and Thorslund, M. 2006. Complex health problems among the oldest old. European Journal of Ageing, 3: 98 - 106.

[34]. Peter T (2011). Adoption of Mobile money technology: Structural Equation Modeling Approach. Eur. J. Bus. Manage. 3(7):2011.

[35]. Pel-Littel R. E., Schuurmans M. J., Emmelot-Vonk M. H. and Verhaar H. J. J. 2009. Frailty: Defining and Measuring of a Concept. The Journal of Nutrition, Health \& Aging, 13: $390-394$.

[36]. Puts, M. T. E, Lips, P., Ribbe, M. W. and Deeg, D. J. H. 2005c. The effect of frailty on residential/nursing home admission in the Netherlands independent of chronic diseases and functional limitations. European Journal of Ageing 2: $264-274$.

[37]. Puts, M. T. E., Lips, P. and Deeg, D. J. H. 2005a. Sex differences in the risk of frailty for mortality independent of disability and chronic diseases. Journal of the American Geriatrics Society, 53 : 40 - 47.

[38]. Puts, M. T. E., Lips, P. and Deeg, D. J. H. 2005b. Static and dynamic measures of frailty predicted decline in performance-based and selfreported physical functioning. Journal of Clinical Epidemiology. 58: $1188-1198$.

[39]. Rockwood, K., Hogan, D. B. and MacKnight, C. 2000. Conceptualisation and measurement of frailty in elderly people. Drugs \& Aging, 17: 295 - 302.

[40]. Salomon J. A., Mathers C.D., Chatterji S., Sadana R., Ustun T.B. and Murray C.J.L. 2003. Quantifying individual levels of health: definitions, concepts and measurement issues. In: Murray C.J.L., Evans D., (editors). Health

[41]. Sorkin, D.H., Pham, E., \& Ngo-Metzger, Q. (2009). Racial and ethnic differences in the mental health needs and access to care of older adults in California. Journal of the American Geriatrics Society, 57(12), 2311-2317.

[42]. Tabachnick BG, Fidell LS (2007). Using Multivariate Statistics, $5^{\text {th }}$ Edn. New York: Allyn and Bacon. In:Hooper D, Coughlan J, Mullen M R (2008). "Structural Equation Modelling: Guidelines for Determining Model Fit." The Electronic J. Bus. Res. Methods 6(1):53-60

[43]. Tanser, F. (2006). "Methodology for optimising location of new primary health care facilities in rural communities: a case study in KwaZulu-Natal, South Africa”, Journal of Epidemiology and Community Health, vol. 60, pp.846-850.

[44]. Torgerson, R., Wortsman, A., and Mcintosh, T. (2006). "Towards a Broader Framework for Understanding Accessibility in Canadian Health Care", Canadian Policy Research Network.

[45]. U.S. Census Bureau. (2003). The older population in the United States: March 2002. Available at: http://www.census.gov/prod/2003pubs/p20-546.pdf.

[46]. United Nations (2002). Report of the second world assembly on ageing: Madrid, 8_12 April 2002. New York: United Nations.

[47]. Wirick, Grover C., Jr. (1966). "A multiple equation model of demand for health care", Health service research 1 ; pp.50-57.

[48]. World Health Organization (2008) Global Burden of Disease: 2004 update. Available at http://www.who.int/healthinfo/global_burden_disease/en/. 
A Structural Equation Model of Elderly Health Care in the Surveyed Households in Kumbakonam ..

[49]. World Health Organization. 1948. Costitution of the World Health Organization. Geneve: World Health Organization

[50]. Zhang, W. D. (2002). Quality of Life and Psychological Health of the Elderly Residents: SEM Analysis. Science of Psychology. 25(3): 307-309 